patients had alcoholic liver disease, many with grossly abnormal liver function, and many were in the upper age range for the condition. As a group such patients must form a poorrisk category whatever treatment is offered. The ultimate result in patients with alcoholic liver disease is influenced by whether or not they continue drinking, a fact which (as all concerned with such patients would agree) is very difficult to establish with certainty. In many cases haemorrhage had not been confirmed by endoscopy, though that should be mandatory in patients with alcoholic liver disease, who may often have alternative sites of bleeding such as peptic ulcers and gastric erosions. ${ }^{\star}$ Despite the results of the recent trials we remain ignorant about the virtues of portacaval shunting for younger and non-alcoholic patients with portal hypertension who present with repeated episodes of variceal haemorrhage.

The natural history of variceal bleeding is variable and depends on the disease category. Studies from the Mayo clinic" have shown that patients with portal hypertension secondary to chronic active hepatitis but on steroid treatment have a low incidence of recurrent variceal haemorrhage. Patients with extrahepatic portal hypertension have a relatively good prognosis for each episode of haemorrhage and should also be considered as a separate group. Whether selection of those patients who will benefit from portacaval shunting will ever be possible is conjectural, for attempts based on haemodynamic or detailed biochemical investigations have generally failed to help. For the present a reasonable policy is to offer elective PCA only to the small group of younger patients (aged 20-30 years) with non-alcoholic portal hypertension and reasonably preserved liver function who have had at least two confirmed episodes of bleeding from gastro-oesophageal varices during the previous 12 months.

This leaves a majority of patients, many with severely impaired liver function, in whom recurrent variceal haemorrhage remains a problem. What other forms of surgery can be offered? Aiming to minimise the risk of post-shunt encephalopathy, Warren ${ }^{10}$ has devised a technique for decompressing varices termed the distal splenorenal shunt. Here blood is selectively shunted from the system of vessels supplying the varices but not from the portal system. He also attempted to predict which patients would develop hepatic encephalopathy by monitoring the mean rate of urea synthesis. Initial reports of this procedure have been encouraging: rates of postoperative bleeding and encephalopathy have been very low. ${ }^{11}$ In the most recent analysis Britton ${ }^{12}$ reviewed 154 patients after procedures of selective shunting up to 96 months and reported an encephalopathy rate of only $8^{\circ}{ }_{1}$.

Direct ligation or transection of varices remains lifesaving as an emergency procedure in a few cases of continuing severe haemorrhage that cannot be controlled by Sengstaken tube, but it has lost its initial popularity as an elective procedure because of the high rate of further bleeding. This assessment was confirmed in a recent paper by Cooperman, ${ }^{13}$ who found that every one of a group of non-cirrhotic patients with portal hypertension bled again despite ligation of the varices.

Recently, more conservative surgical procedures have been described, such as attempts directly to thrombose the varices or the vessels supplying them. An oesophagogastroscope is used to inject a sclerosing agent directly into the varices. Regular follow-up of the patient is needed with repeated injections until the varices have been obliterated. A second technique uses a transhepatic approach with selective catheterisation of the left gastric and short gastric veins and injection of dextrose, thrombin, and gelatin foam ${ }^{14}$ to induce thrombosis. Unfortunately there seems to be a high frequency of recanalisation and further bleeding. Both techniques require expertise if complications are to be avoided and they are available in only a few specialised centres. Controlled trials are now in progress. Finally, some workers would argue that liver transplantation (the results of which have improved greatly during the past 18 months) may be the only possible approach in a few selected young patients with endstage cirrhosis in whom repeated bleeding from massive varices remains uncontrolled.

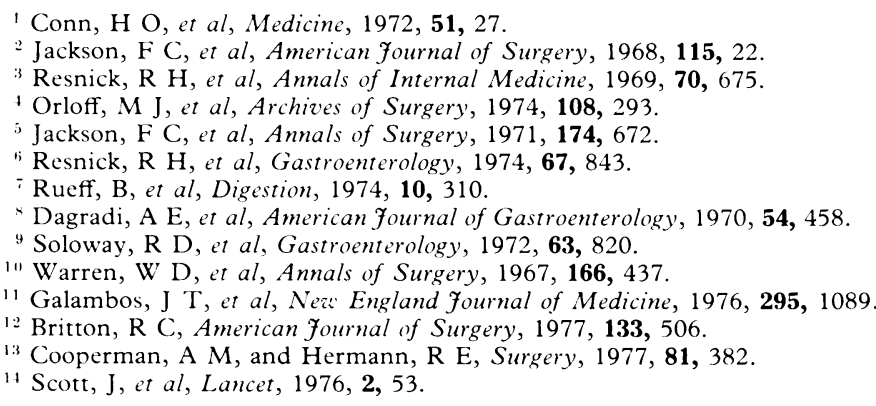

\section{Pathogenesis of osteoarthrosis}

Of the many types of joint disease osteoarthrosis is the most common, yet it has excited the least attention. Interest has increased recently, however, and recent studies ${ }^{1-3}$ have challenged cherished concepts. The "wear and tear" explanation now appears sufficiently shaky for the Arthritis and Rheumatism Council to have withdrawn from its handbook for patients a cartoon that depicts a doctor's decrepit car as the best analogy of osteoarthrosis.

In her Heberden oration ${ }^{4}$ Helen Muir described studies of osteoarthrosis induced in dogs by severing the cruciate ligaments of the knee ${ }^{5}$ and suggested that in the initial stages there appear to be profound changes in the metabolism of cartilage cells, set in train by increased hydration of the tissue; only at an advanced stage does the disease process become degenerative. Abnormal hydration of the cartilage is also known to occur in human osteoarthrosis. ${ }^{6} 7$

Series of studies from Leeds ${ }^{8}{ }^{10}$ have also cast doubt on a simple wear and tear explanation. Individuals thought to be liable to osteoarthrosis by virtue of their occupation or sport -professional footballers, ${ }^{11-13}$ pneumatic drillers, ${ }^{14}$ and parachutists ${ }^{15}$ - have been found to have no more joint degeneration than the rest of the population. Moreover, 25 grossly obese patients showed no more osteoarthrosis than average. ${ }^{16}$ Among the parachutists the only factor more common in those with osteoarthrosis was meniscectomy, a well-known association. ${ }^{15}$

Examination of degenerate cartilage through the scanning electron microscope suggests mechanical failure, ${ }^{17}$ and careful studies at Imperial College, London, have shown cartilage to be fatigue-prone. ${ }^{18}$ The appearance of the cartilage that has undergone fatigue failure by cyclical compressive loading in vitro resembles that of fibrillated cartilage. ${ }^{18} 19$

Radin, who also favours mechanical factors as an explanation for osteoarthrosis, lays emphasis on the underlying bone. ${ }^{20} \mathrm{He}$ describes the disease as a physiological imbalance between the stress applied to the cartilage and the ability of the shock- 
absorbing mechanisms (mainly bone) to attenuate and dampen the applied forces. In favour of this theory are the greater bone density in patients with osteoarthrosis of the hip and the rarity of the disease in patients who have fractured the upper end of the femur and who usually have osteoporosis. ${ }^{21}$ The same process may well account for the low prevalence of osteoarthrosis in a late review of patients with anterior poliomyelitis affecting the legs. ${ }^{22}$ Byers made an important contribution when he showed a histological distinction (in necropsies) between "limited alterations" and progressive disease. ${ }^{23}$.35 It was limited alterations that were found in the femoral head in the areas of habitual non-use by Bullough et al, ${ }^{26}$ who believed that the areas in the dome of the hip came into excessive contact with the head as the incongruity of the acetabulum diminished with age. This set up a progressive alteration in the head, which ultimately reacted on the acetabulum.

Further evidence in favour of a mechanical explanation of osteoarthrosis is the location of lesions in the patellofemoral joint. These correspond ${ }^{2}{ }^{28}$ to the contact areas of angles of flexion of the knee between 40 and 80 -the angles at which the peak loads occur. But this brings us back to the question: Why don't the joints of all people show degenerative changes? In some patients there is an obvious predisposing causeindeed, of 327 patients whose osteoarthrotic hips had been removed at surgery, Solomon ${ }^{29}$ believed he could identify a cause in all but 27 . In others an inflammatory element may be prominent, ${ }^{30}$ possibly provoked by apatite crystals, ${ }^{31}$ though whether this is a primary or secondary phenomenon is not clear. Muir's explanation ${ }^{4}$ of the predisposition of some people to develop osteoarthrosis is that individuals vary considerably in the amounts and topographical distribution of collagen, chondroitin sulphate, and keratan sulphate in the articular cartilage. ${ }^{32} 33$

These questions are not only of academic interest: they have important implications for the prevention of the disease, for the development of drugs to halt its progress, and even for the type of surgery best suited to individual patients. At present mechanical factors seem to be important in the production of osteoarthrosis, but an explanation solely on the basis of wear and tear has become too simple.

\footnotetext{
1 Sokoloff, L, The Biology of Degenerative Foint Disease. Chicago, University of Chicago Press, 1969.

2 Freeman, M A R, Adult Articular Cartilage. London, Pitman, 1973.

${ }^{3}$ Wright, V, Clinics in Rheumatic Diseases, 1976, 2, No 3.

- Muir, H, Annals of the Rheumatic Diseases, 1977, 36, 199.

${ }^{5}$ Pond, M J, and Nuki, G, Annals of the Rheumatic Diseases, 1973, 32, 387.

${ }^{6}$ Bollet, A J, and Nance, J L, Fournal of Clinical Investigation, 1966, 45, 1170.

${ }^{7}$ Mankin, H J, and Thrasher, A Z, fournal of Bone and foint Surgery, 1975, 57A, 76.

${ }^{8}$ Adams, I D, Clinics in Rheumatic Diseases, 1976, 2, 523.

${ }^{9}$ Burke, M J, Fear, E C, and Wright, V, Annals of the Rheumatic Diseases, 1977, 36, 276

1" Murray-Leslie, C F, Lintott, D J, and Wright, V, Annals of the Rheumatic Diseases, 1977, 36, 327.

11 Brodelius, A, Acta Orthopaedica Scandinavica, 1960 1961, 30, 309

12 Pellingrini, P, Nibbio, N, and Piffanelli, A, Archispedale S Anna di Ferrara, 1964, 17, 879

${ }^{13}$ Solonen, K A, Annals Chirurgiae et Gynaecologiae Fenniae, 1966, 55, 176.

14 Radin, E L, Paul, I L, and Rose, R M, Lancet, 1972, 1, 519.

15 Jackson, J P, British Medical fournal, 1968, 2, 525.

16. Goldin, R H, et al, Annals of the Rheumatic Diseases, 1976, 35, 349.

17 Minns, R J, Steven, F S, and Hardinge, K, Fournal of Pathology, 1977, 122, 63.

1* Weightman, B O, Freeman, M A R, and Swanson, S A V, Nature, 1973,
} 244, 303.
${ }^{19}$ Johnson, G, Dowson, D, and Wright, V, Proceedings of the 3rd Leeds-Lyon Symposium on Tribology, 1977, in press.

2" Radin, E L, Bulletin of the Rhe'umatic Diseases, 1976, 26, 862.

2 Foss, M L V, and Byers, P D, Annals of the Rheumatic Diseases, 1972, 31, 259.

2.2 Glyn, J H, et al, British Medical fournal, 1966, 2, 739.

23 Byers, P D, Contepomi, C A, and Farkas, T A, Annals of the Rheumatic Diseases, 1970, 29, 15.

24 Byers, P D, Contepomi, C A, and Farkas, T A, Annals of the Rheumatic Diseases, 1976, 35, 114

2.5 Byers, P D, Contepomi, C A, and Farkas, I A, Annals of the Rheumatic Diseases, 1976, 35, 122

26 Bullough, P G, Goodfellow, J, and O'Connor, J J, Fournal of Bone and foint Surgery, 1973, 55B, 746 .

2- Meachim, G, and Emery, I H, Annals of the Rheumatic Diseases, 1974, 33, 39.

* Seedhom, B B, Biomechanics of Patello-Femoral ()steoarthrosis. Workshop on Models of Osteoarthrosis, 1977, in press.

29 Solomon, L, fournal of Bone and foint Surgery, 1976, 58B, 176

30 Ehrlich, G E, Fournal of the American Medical Association, 1975, 232, 157.

Dieppe, P A, et al, Lancet, 1976, 1, 266.

32 Muir, H, Maroudas, A, and Wingham, J, Biochimica et Biophysica Acta, $1969, \mathbf{1 7 7}, 494$

33 Kempson, G E, et al, Biochmica et Biophysica Acta, 1973, 297, 456.

\section{Names of drugs}

Our reluctance to consider printing the proprietary names of drugs in $B M \mathcal{F}$ articles has stimulated further correspondence this week ( $p$ 1024). There is a good case for including the name of the specific preparation used in reports of side effects and in trials of new drugs, since a proprietary or non-proprietary "equivalent" may differ in the preservatives used or in bioavailability. The real problems arise with teaching and review articles in the Medical Practice section, which may mention a score or so of commonly used drugs on a single page. While we recognise the irritation that may be caused our readers by our description of all these drugs simply by their approved or generic names, there is no satisfactory alternative. We tried to provide a glossary of the manufacturers' names a few years ago, but it proved dauntingly difficult. What do we do, for example, when an article refers to prednisolone? MIMS lists Codelcortone, Codelsol, Cordex, Cordex Forte, Delta-Cortef, Deltacortril, Deltastab, Di-Andreson, Precortisyl, Prednesol, and Sinitisone, and a further group of various methylprednisolone preparations. Similar lists need to be made for compounds such as phenobarbitone, and indeed any widely prescribed drug that is no longer covered by patent. New proprietaries are introduced each month, others are withdrawn; but pharmaceutical firms are rightly indignant if their latest product is omitted from such lists. About one-quarter of $B M \mathcal{F}$ readers live outside Britain, and drugs used in all parts of the world (such as ampicillin or propranolol) may have different proprietary names in each continent.

In practical terms, most doctors have a British National Formulary on their desks, which includes a reasonably comprehensive glossary of proprietary drugs with their approved names. A similar list is published by the British Pharmacopoeia Commission. The range of drugs prescribed by any individual is remarkably narrow, and once the decision is taken to "think generic" surely the effort required is small. 